\title{
RfpA, RfpB, and RfpC are the Master Control Elements of Far-Red Light Photoacclimation (FaRLiP)
}

\author{
Chi Zhao ${ }^{1}$, Fei Gan ${ }^{1 \dagger}$, Gaozhong Shen ${ }^{1}$ and Donald A. Bryant ${ }^{1,2 *}$ \\ ${ }^{1}$ Department of Biochemistry and Molecular Biology, The Pennsylvania State University, University Park, PA, USA, \\ ${ }^{2}$ Department of Chemistry and Biochemistry, Montana State University, Bozeman, MT, USA
}

OPEN ACCESS

Edited by: Martin G. Klotz,

Queens College of The City University of New York, USA

Reviewed by:

Min Chen,

University of Sydney, Australia

Ferran Garcia-Pichel,

Arizona State University, USA

*Correspondence:

Donald A. Bryant

dab14@psu.edu

${ }^{\dagger}$ Present Address:

Fei Gan,

The Scripps Research Institute, La Jolla, CA, USA

Specialty section:

This article was submitted to Microbial Physiology and Metabolism,

a section of the journal

Frontiers in Microbiology

Received: 11 September 2015 Accepted: 06 November 2015 Published: 25 November 2015

Citation:

Zhao C, Gan F, Shen G and Bryant DA (2015) RfpA, RfpB, and RfpC are the Master Control Elements of Far-Red Light Photoacclimation (FaRLiP).

Front. Microbiol. 6:1303.

doi: 10.3389/fmicb.2015.01303
Terrestrial cyanobacteria often occur in niches that are strongly enriched in far-red light (FRL; $\lambda>700 \mathrm{~nm}$ ). Some cyanobacteria exhibit a complex and extensive photoacclimation response, known as FRL photoacclimation (FaRLiP). During the FaRLiP response, specialized paralogous proteins replace 17 core subunits of the three major photosynthetic complexes: Photosystem (PS) I, PS II, and the phycobilisome. Additionally, the cells synthesize both chlorophyll (Chl) $f$ and Chl $d$. Using biparental mating from Escherichia coli, we constructed null mutants of three genes, rfpA, rfpB, and rfpC, in the cyanobacteria Chlorogloeopsis fritschii PCC 9212 and Chroococcidiopsis thermalis PCC 7203. The resulting mutants were no longer able to modify their photosynthetic apparatus to absorb FRL, were no longer able to synthesize Chl $f$, inappropriately synthesized $\mathrm{Chl} d$ in white light, and were unable to transcribe genes of the FaRLiP gene cluster. We conclude that RfpA, RfpB, and RfpC constitute a FRL-activated signal transduction cascade that is the master control switch for the FaRLiP response. FRL is proposed to activate (or inactivate) the histidine kinase activity of RfpA, which leads to formation of the active state of RfpB, the key response regulator and transcription activator. RfpC may act as a phosphate shuttle between RfpA and $\mathrm{RfpB}$. Our results show that reverse genetics via conjugation will be a powerful approach in detailed studies of the FaRLiP response.

Keywords: photosynthesis, photosystem I, photosystem II, phycobilisome, chlorophyll $f$, chlorophyll $d$, Chlorogloeopsis fritschii PCC 9212, Chroococcidiopsis thermalis PCC 7203

\section{INTRODUCTION}

Terrestrial cyanobacteria often occur in niches that are strongly enriched in far-red light (FRL; $\lambda>$ $700 \mathrm{~nm}$ ). Soil and fresh-water cyanobacteria encounter FRL because it penetrates more deeply into soils and because plant canopies strongly enrich for FRL because of absorption by chlorophylls (Chl) $a$ and $b$ (Gan and Bryant, 2015). Similar effects occur in microbial mats and sometimes in blooms, where self-shading can provide a powerful selection for alternative, light-harvesting antenna systems (Kühl and Jørgensen, 1994; Nowack et al., 2015; Olsen et al., 2015). We recently discovered two photoacclimation processes that occur in some cyanobacteria in FRL and/or low light, here denoted Far-Red Light Photoacclimation (FaRLiP) (Gan et al., 2014, 2015; Gan and Bryant, 2015) and Low Light Photoacclimation (LoLiP) (Nowack et al., 2015; Olsen et al., 2015).

Abbreviations: Chl, chlorophyll; FaRLiP, Far-Red Light Photoacclimation; FRL, far-red light; HEPES, 4-(2-hydroxyethyl)-1piperazineethanesulfonic acid; LoLiP, Low-Light Photoacclimation; WL, white light. 
During the FaRLiP response, specialized paralogous proteins replace 17 core subunits of the three major photosynthetic complexes: Photosystem (PS) I, PS II, and the phycobilisome. Additionally, the cells synthesize both Chl $f$ and Chl $d$ (Gan et al., 2014, 2015). The net impact is that the remodeled photosynthetic apparatus confers the ability to absorb light between 700 and $800 \mathrm{~nm}$, and thus cells are able to grow in FRL. The LoLiP response occurs within low-light-adapted ecotypes of Synechococcus spp. in microbial mats associated with Mushroom Spring in Yellowstone National Park. In this acclimation response, cells only synthesize $\mathrm{Chl} a$, but a three-gene operon, apcD4-apcB3-isiX, is expressed that leads to absorption beyond $700 \mathrm{~nm}$, and cells exhibit improved growth at low irradiance (Nowack et al., 2015; Olsen et al., 2015). The apcD4apcB3-isiX operon does not occur in high-light-adapted ecotypes of Synechococcus sp. (Olsen et al., 2015), but these genes do occur sporadically in some other cyanobacteria (Gan et al., 2015).

Analyses of all publicly available cyanobacterial genomes show that 13 cyanobacteria have the gene cluster that confers the capacity for FaRLiP (Gan et al., 2014, 2015). Three other cyanobacteria have been shown to synthesize $\operatorname{Chl} f$ when grown in light conditions consistent with FaRLiP, and presumably these strains will also contain similar gene clusters (Gan and Bryant, 2015). Each FaRLiP gene cluster contains a three-gene operon, $r f p B-r f p A-r f p C$, that encodes regulatory proteins. RfpA is a red/far-red, knotless phytochrome, and these proteins form a distinctive structural family of cyanobacterial photoreceptors (Gan et al., 2014). RfpA has a histidine kinase domain and is proposed to act as the sensor kinase in a signal transduction cascade. RfpB is the response regulator and contains a wingedhelix, DNA-binding domain as well as two CheY-like domains. $\mathrm{RfpC}$ is also a CheY-like protein and may act to transfer a phosphate from $\mathrm{RfpA}$ to $\mathrm{RfpB}$. Although there is strong circumstantial evidence that the products of these three genes are the primary regulatory proteins of the FaRLiP response, because no genetic system had been developed in any verified FaRLiP strain, this point has not been directly demonstrated until now.

In the work reported here, we selected two common, terrestrial cyanobacteria, Chlorogloeopsis fritschii PCC 9212 and Chroococcidiopsis thermalis PCC 7203 (hereafter Chl. fritschii PCC 9212 and Chr. thermalis PCC 7203), which perform FaRLiP to demonstrate that $\mathrm{RfpA}, \mathrm{RfpB}$, and $\mathrm{RfpC}$ are the master control elements of the response to FRL. Chl. fritschii is a developmentally complex cyanobacterium belonging to the order Stigonematales (subsection 5, Cyanobacteria) (Evans et al., 1976; Hoffman and Castenholz, 2001). The type strain of Chl. fritschii (strain PCC 6912) was isolated by Mitra and Pandey from soil in India (Mitra and Pandey, 1967), but Chl. fritschii strains are also reported to occur in hot springs worldwide at temperatures up to $63-64^{\circ} \mathrm{C}$. The strain used in the studies reported here, Chl. fritschii PCC 9212 was isolated from a hot spring in Ourense, Spain. Despite these very different habitats, the genomes of the two Chl. fritschii isolates, PCC 6912 and 9212, are very similar.

Chr. thermalis PCC 7203 was initially described as a "primitive" cyanobacterium (Friedmann et al., 1994; Friedmann and Ocampo-Friedmann, 1995), but its large genome and a complex developmental cycle involving the production of non-motile baeocytes contradicts this notion. Furthermore, phylogenetic analyses show that Chroococcidiopsis spp. is not a member of the order Pleurocapsales, but rather that its closest relatives are heterocystous cyanobacteria (Nostocales and Stigonematales) (Fewer et al., 2002). Chroococcidiopsis spp. are extremely desiccation resistant and are among the most resistant organisms known against ionizing radiation (Billi et al., 2001). Chr. thermalis PCC 7203 was isolated from soil, but members of this genus are often endoliths and/or hypoliths and are found in a wide range of extreme environments, including hot and cold deserts, soils, hot springs, and caves as well as in freshwater, marine and hypersaline conditions (Friedmann et al., 1994; Friedmann and Ocampo-Friedmann, 1995). Note that many of these environments produce light conditions enriched in FRL, and thus not surprisingly, Chr. thermalis PCC 7203 has a FaRLiP gene cluster (Gan et al., 2014, 2015).

In this study we show that DNA can be introduced by conjugation into Chl. fritschii PCC 9212 and Chr. thermalis PCC 7203 and that gene deletions can be obtained by double recombination without the necessity to counter-select with sucrose/SacB. Using this approach, we constructed deletion mutations for $r f p A, r f p B$ and $r f p C$. The phenotypes of these mutants establish that $\mathrm{RfpA}, \mathrm{RfpB}$ and $\mathrm{RfpC}$ form the master control switch for the FaRLiP response. These studies set the stage for more exhaustive use of reverse genetics to study the roles the paralogous FaRLiP genes in facilitating growth in FRL.

\section{MATERIALS AND METHODS}

\section{Strains and Growth Conditions}

The cyanobacterial strains used in this study were obtained from the Pasteur Culture Collection (http://www.pasteur.fr/ pcc_cyanobacteria) (Rippka et al., 1979; Rippka, 1988). Chl. fritschii PCC 9212 was isolated from a hot spring near Ourense, Spain. Chr. thermalis PCC 7203 was isolated from soil near Greifswald, Germany. These two strains were grown in the BHEPES growth medium (Dubbs and Bryant, 1991), a modified BG11 medium containing $1.1 \mathrm{~g} \mathrm{~L}^{-1}$ 4-(2-hydroxyethyl)-1piperazineethanesulfonic acid (HEPES) (final concentration) with the $\mathrm{pH}$ adjusted to 8.0 with $2.0 \mathrm{M} \mathrm{KOH}$. Warm white fluorescent lights provided continuous illumination at $\sim 250 \mu \mathrm{mol}$ photons $\mathrm{m}^{-2} \mathrm{~s}^{-1}$ (WL), and liquid cultures were sparged with $1 \%(\mathrm{v} / \mathrm{v}) \mathrm{CO}_{2}$ in air. FRL was provided by LEDs (Marubeni, Santa Clara, CA) with emission centered at $720 \mathrm{~nm}\left(15-18 \mu \mathrm{mol}\right.$ photons $\left.\mathrm{m}^{-2} \mathrm{~s}^{-1}\right)$. Plastic filters, the transmittance properties of which have been previously described (Gan et al., 2014), were sometimes used to produce green light (GL), red light (RL), and FRL. Growth of cells was monitored turbidometrically at $730 \mathrm{~nm}$ by using a GENESYS 10 spectrophotometer (ThermoSpectronic, Rochester, NY).

\section{Construction of Mutants and Conjugation}

The biparental conjugation system was kindly provided by Professor Jindong Zhao from Peking University (Zhao et al., 2005). The donor E. coli strain HB101 contained the conjugal plasmid pRL443 and the helper plasmid pRL623 (Elhai and Wolk, 
1988; Elhai et al., 1997). To generate constructs for deletion of the $r f p A, r f p B$, or $r f p C$ genes, an ermC cassette, which confers resistance to erythromycin, was amplified through PCR and cloned onto the cargo plasmid pRL277 using SacI and SphI restriction sites (see Table S1 for primer sequences). For each of the target genes, upstream and downstream DNA fragments with a size of $\sim 2.5-3.0 \mathrm{~kb}$ were amplified by PCR using Phusion ${ }^{\circledR}$ HF DNA polymerase (New England Biolabs, Ipswich, MA, USA). The primers for DNA fragment amplification of the upstream and downstream regions of $r f p A, r f p B$, and $r f p C$ genes from Chl. fritschii PCC 9212 and Chr. thermalis PCC 7203 rfpA and $r f p B$ are listed in Table S1. Upstream and downstream DNA fragments for each target gene were cloned onto the cargo plasmid pRL277 with an interposing DNA fragment encoding erm $C$ to replace the target gene through a double-crossover recombination event.

Cargo plasmids were transformed into the donor E. coli HB101 cells containing the conjugal plasmid pRL443 and the helper plasmid pRL623. The resulting E. coli HB101 strains were grown in 5-20 ml of Luria-Bertani (LB) medium supplemented with appropriate antibiotics and cultured at $37^{\circ} \mathrm{C}$ overnight.
The E. coli cells were harvested by centrifugation at low speed, washed with fresh LB medium three times, and resuspended in fresh LB or B-HEPES medium (100-200 $\mu \mathrm{l})$. Meanwhile, freshly grown wild-type Chl. fritschii PCC 9212 or Chr. thermalis PCC 7203 cells $\left(\mathrm{OD}_{730 \mathrm{~nm}}=0.6-1.0 ; 500 \mu \mathrm{l}\right.$ to $\left.2.0 \mathrm{ml}\right)$ were centrifuged at low speed, washed with fresh B-HEPES medium three times, and finally resuspended in B-HEPES medium (100$200 \mu \mathrm{l}$ ). The E. coli and cyanobacterial cells were gently mixed in a sterile microcentrifuge tube and incubated at $30^{\circ} \mathrm{C}$ under low light for 4-6 h, and the cell mixture was then spread onto a sterile nitrocellulose filter overlaid on a B-HEPES agar plate without antibiotics. The plate was incubated at $30^{\circ} \mathrm{C}$ under low light for another $18-36 \mathrm{~h}$, and then the filter was transferred to a B-HEPES agar plate containing $20 \mu \mathrm{g}$ erythromycin $\mathrm{ml}^{-1}$. Green-colored colonies appeared on the filter after 4-6 weeks; they were picked and streaked repeatedly on selective medium, and the purified transconjugant cells were ultimately transferred to liquid B-HEPES medium for analyses. Segregation of wild-type and mutant alleles of the target gene was analyzed by colony PCR and by PCR analysis of cells from liquid cultures.

\section{A

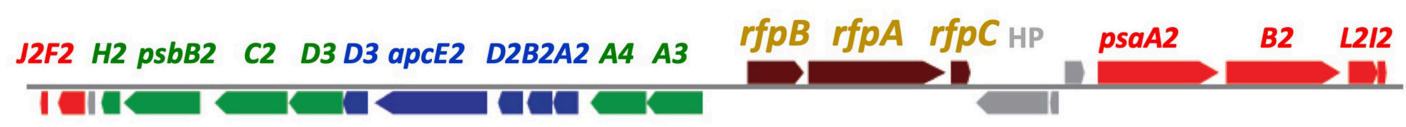

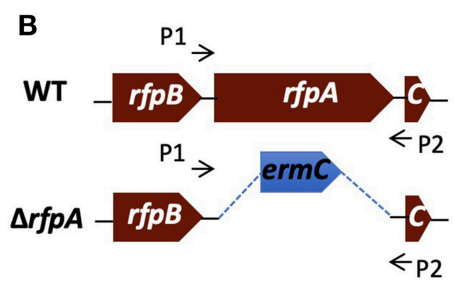

E

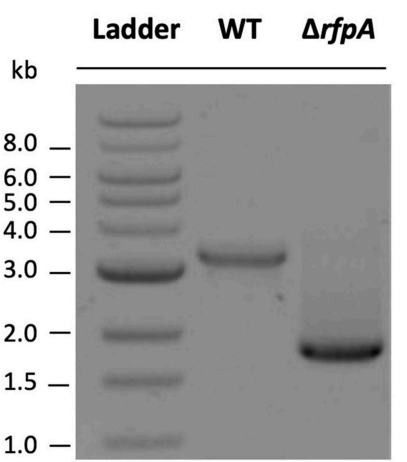

C

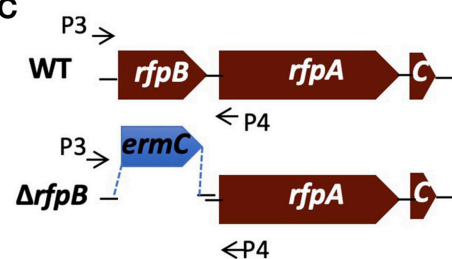

$\mathbf{F}$

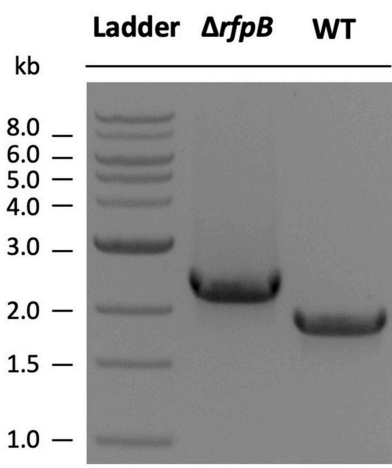

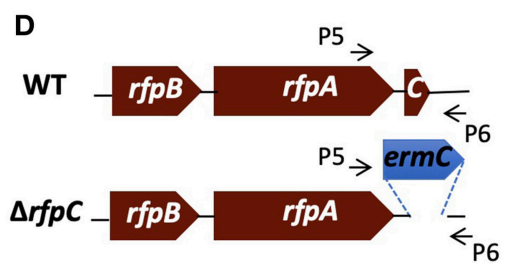

G

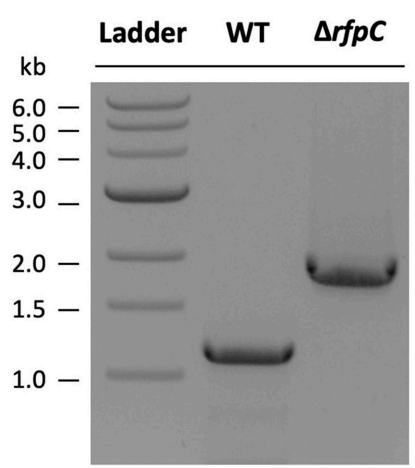

FIGURE 1 | The organization of the FaRLiP gene cluster in Chl. fritschii PCC 9212 and construction and validation of $r f p A$, rfpB, and rfpC deletion mutants. (A) Gene organization of the FaRLiP gene cluster in Chl. fritschii PCC 9212. Red boxes represent genes encoding core subunits of PS I; green boxes represent genes encoding core subunits of PS II; blue boxes represent genes encoding core components of the phycobilisome; brown boxes represent regulatory rfp genes; and gray boxes represent genes that are not found in other FaRLiP clusters. (B) Schematic showing deletion of rfpA. The small arrows (P1 and P2) indicate the positions of the primers used for PCR verification of deletion. (C) Schematic showing deletion of rfpB. The small arrows (P3 and P4) indicate the positions of primers used for PCR verification of the deletion. (D) Schematic showing deletion of rfpC. The small arrows (P5 and P6) indicate the positions of primers used for PCR verification of the deletion. (E) Agarose gel electrophoresis of amplicons showing complete segregation of wild-type and mutant ifpA alleles. (F) Agarose gel electrophoresis of amplicons showing complete segregation of wild-type and mutant $r f p B$ alleles. (G) Agarose gel electrophoresis of amplicons showing complete segregation of wild-type and mutant $r f p C$ alleles. 


\section{Pigment Measurements and Absorption and Fluorescence Spectroscopy}

The Chl and carotenoid contents of cells were measured from pigments extracted with 100\% methanol. Spectroscopic measurements were performed with a GENESYS $10 \mathrm{UV}-$ Vis spectrophotometer (Thermo Scientific). The Chl a concentration was determined on the basis of equivalent cell concentrations as determined by equal $\mathrm{OD}_{730 \mathrm{~nm}}$ values as described (Shen et al., 2008). To measure the absorption spectra of whole cells, cells from liquid cultures were harvested and resuspended in $10 \%(\mathrm{w} / \mathrm{v})$ sucrose prepared with $50 \mathrm{mM}$ HEPES buffer, $\mathrm{pH}$ 7.0. Homogenization with a Teflon/glass homogenizer was used to achieve a more homogenous suspension of the filamentous cells of the cyanobacterial strains employed in this study. Absorption spectra of cell cultures were measured with a UV-Vis-NIR Cary ${ }^{\mathrm{TM}} 14$ spectrophotometer that was modified for computerized data collection and analysis by On-Line Instrument Systems, Inc. (Bogart, GA).
Fluorescence emission spectra at low temperature $(77 \mathrm{~K})$ were measured using an SLM Model 8000C spectrofluorometer that was modified for computerized solid-state operation by Online Instrument Systems Inc., (Bogart, GA) (Shen et al., 2008). Wild-type and mutant cells were harvested from liquid medium and resuspended in $50 \mathrm{mM}$ HEPES/ $\mathrm{NaOH} \mathrm{pH}=7.0$ buffer containing $60 \%(\mathrm{v} / \mathrm{v})$ glycerol by gentle homogenization. After loading samples into the measuring tubes, cells were quickly frozen in liquid nitrogen. To measure the fluorescence emission from Chl-protein complexes, the excitation wavelength was 440 $\mathrm{nm}$, which selectively excites Chls.

\section{Pigment Extraction and HPLC Analysis}

For pigment extraction and HPLC analyses, cyanobacterial cells were harvested and washed once in $50 \mathrm{mM} \mathrm{HEPES} / \mathrm{NaOH}$ buffer, pH 7.0 by centrifugation, resuspension, and subsequent centrifugation. Pigments were extracted from the cell pellet by sonication in acetone:methanol $(7: 2, \mathrm{v} / \mathrm{v})$ under dim light (Graham and Bryant, 2008; Gan et al., 2014). After centrifugation

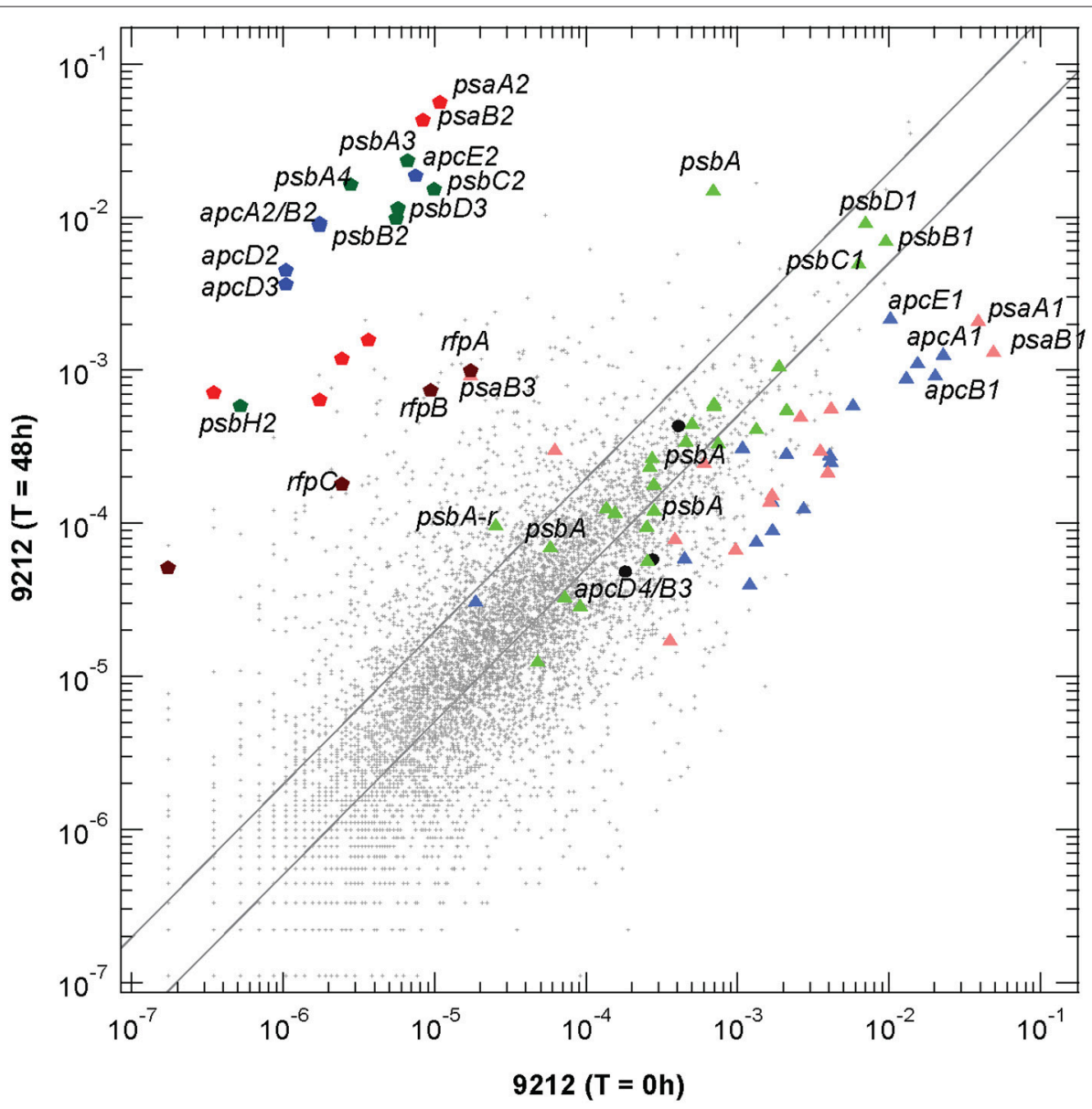

FIGURE 2 | Scatter plot of relative transcript abundances for Chl. fritschii PCC 9212 cells grown for $48 \mathrm{~h}$ in FRL compared to the $T=0$ control (white light). The pentagon symbols represent the genes shown in Figure 1A with the same color coding. Triangular symbols represent genes expressed independent of light quality (i.e., white light). Green triangles represent genes encoding PS II subunits; pale red triangles represent genes encoding PS I subunits; and blue triangles represent genes encoding phycobiliproteins and related proteins (e.g., linker proteins). The three black circles represent the apcD3-apcB4-isiX gens of the LoLiP gene cluster (see text and Table S2 for more details). The parallel lines indicate a two-fold increase and a $50 \%$ decrease in relative transcript abundance. 
to remove protein and other insoluble cell debris, pigment solutions were filtered through $0.2 \mu \mathrm{m}$ polytetrafluoroethylene membrane syringe filters. Pigments were analyzed by reversedphase HPLC on a $25 \mathrm{~cm} \times 4.6 \mathrm{~mm}$ analytical Discovery C18 column (Supelco, Bellefonte, PA) using an Agilent Model 1100 HPLC system equipped with a model G1315B diode array detector. The solvent system and elution conditions were identical to those previously described (Gan et al., 2014).

\section{Transcription Profiling by RNA-SEQ Analysis}

Cells grown continuously in WL were inoculated into three tubes with fresh B-HEPES medium at $\mathrm{OD}_{750 \mathrm{~nm}}=0.05$ and sparged with $1 \%(\mathrm{v} / \mathrm{v}) \mathrm{CO}_{2}$. When cells grew to $\mathrm{OD}_{750 \mathrm{~nm}}=\sim 0.6$, a $15-\mathrm{mL}$ aliquot of culture was collected from each of the three tubes and combined. The combined culture sample was rapidly centrifuged at $4^{\circ} \mathrm{C}$, and the resulting cell pellet was quickly frozen with liquid nitrogen and stored at $-80^{\circ} \mathrm{C}(T=0 \mathrm{~h}, \mathrm{WL}$ sample). The remainder of the cultures were transferred to FRL. Aliquots of cells ( $45 \mathrm{~mL}$ in total) of cells were collected at 12 , 24 , and $48 \mathrm{~h}$, centrifuged, and stored as described above (samples $T=12 \mathrm{~h}, T=24 \mathrm{~h}, T=48 \mathrm{~h}$ ). One additional sample was prepared from cells grown in FRL for 2 weeks ( $336 \mathrm{~h}$; designated as sample FR in Table S2). For RNA isolation, cell pellets were suspended in $50 \mathrm{mM}$ Tris- $\mathrm{HCl}, \mathrm{pH}$ 8.0. An equal volume of glass beads was mixed with the cell suspension, which was then
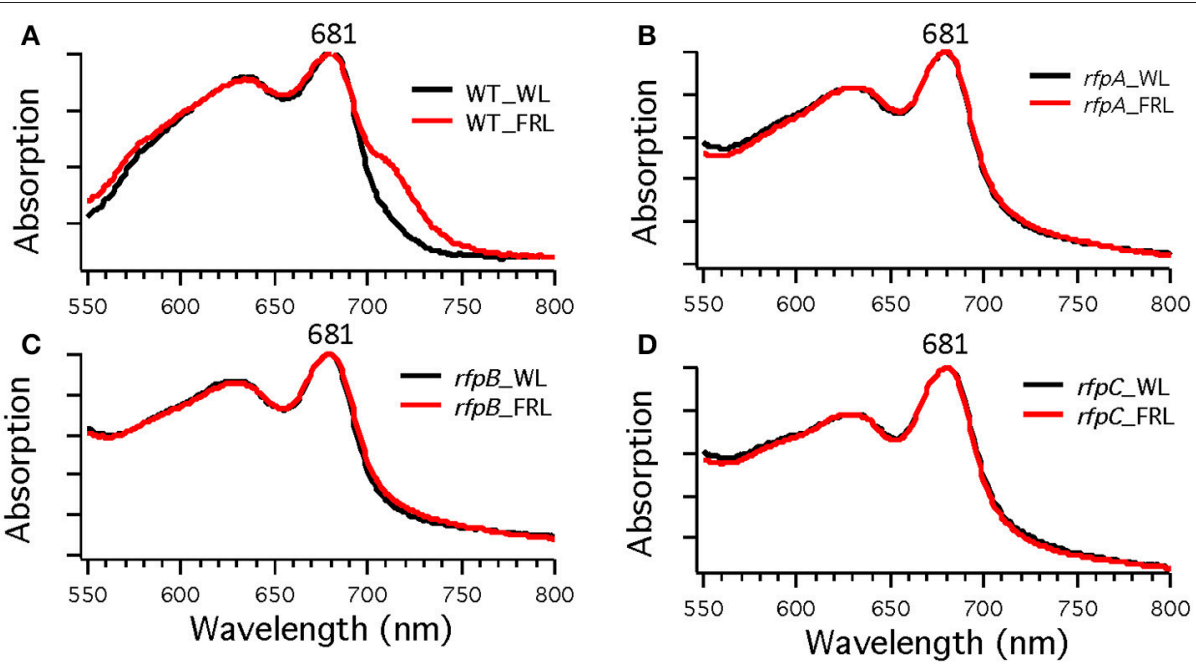

FIGURE 3 | Whole-cell absorption spectra of Chl. fritschii PCC 9212 wild-type (WT) in (A), rfpA mutant in (B), rfpB mutant in (C), and rfpC in (D). Cells were grown in white light (black lines) or grown in FRL (red lines).
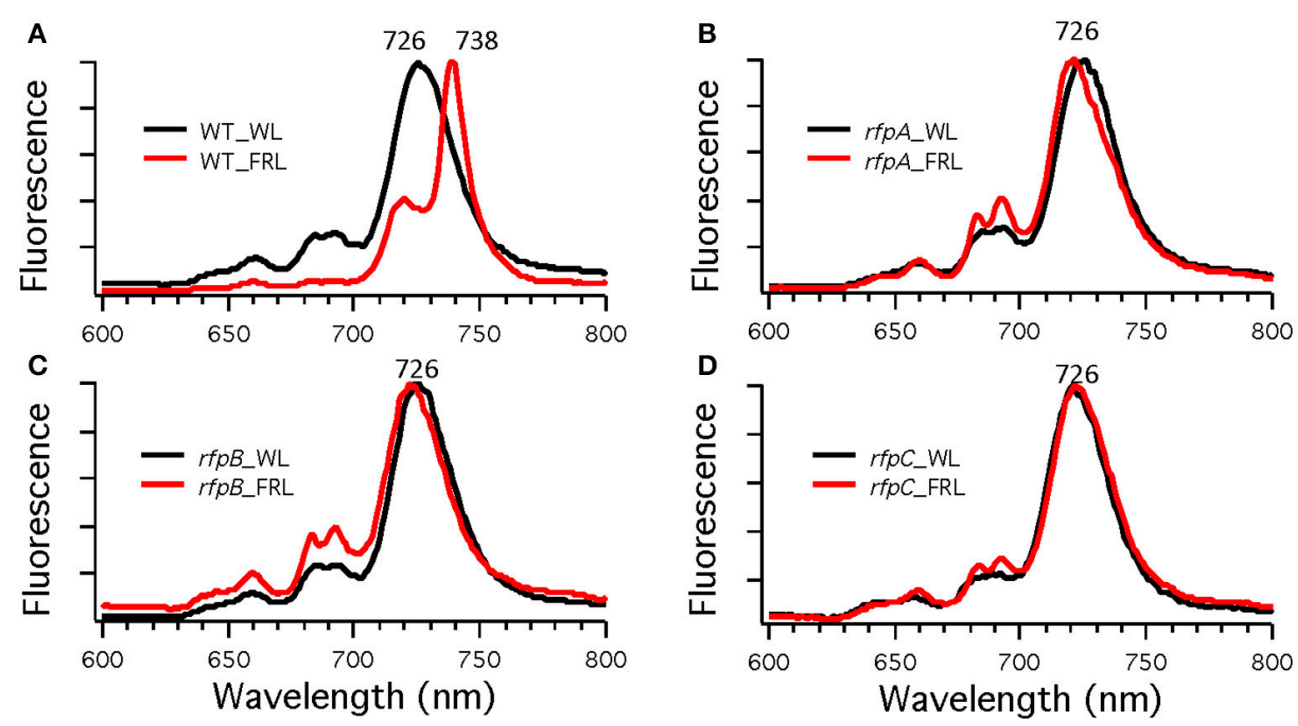

FIGURE 4 | Low-temperature (77 K) fluorescence emission spectra of of Chl. fritschii PCC 9212 wild-type (WT) in (A), rfpA mutant in (B), rfpB mutant in (C), and $r f p C$ in (D). Cells were grown in white light (WL; black lines) or grown in far-red light (FRL; red lines). The excitation wavelength was $440 \mathrm{~nm}$ to excite Chls preferentially. 
subjected to a brief bead beating ( $4200 \mathrm{rpm}$ for $10 \mathrm{~s}$ ) with a minibeadbeater (Biospec Products, Bartlesville, OK). Total RNA was extracted with phenol and further purified as described (Ludwig and Bryant, 2011) with High Pure RNA Isolation Kit (Roche, Indianapolis, IN).

Following the manufacturer's instructions, ribosomal RNA was removed using Ribo-Zero ${ }^{\mathrm{TM}}$ rRNA Removal Kit for bacteria (Epicenter, Madison WI) to obtain enriched mRNA. Construction of the cDNA library and Illumina sequencing was performed in the Genomics Core Facility, The Pennsylvania State University, University Park. Libraries were prepared from enriched mRNA using the TruSeq Stranded mRNA Sample Prep Kit (Illumina, San Diego, CA) according to the manufacturer's instructions with the exception that the poly-A selection steps at the beginning of the protocol were omitted. Samples were sequenced on an Illumina HiSeq 2500 instrument in Rapid Run mode by performing 50-nt single read sequencing according to the instructions of the manufacturer. Mapping against the Chl. fritschii PCC 9212 genome was performed using the BWA software package using scripts modified to accommodate the Illumina sequences ( $\mathrm{Li}$ and Durbin, 2009). The resulting alignment files were further analyzed with self-developed scripts

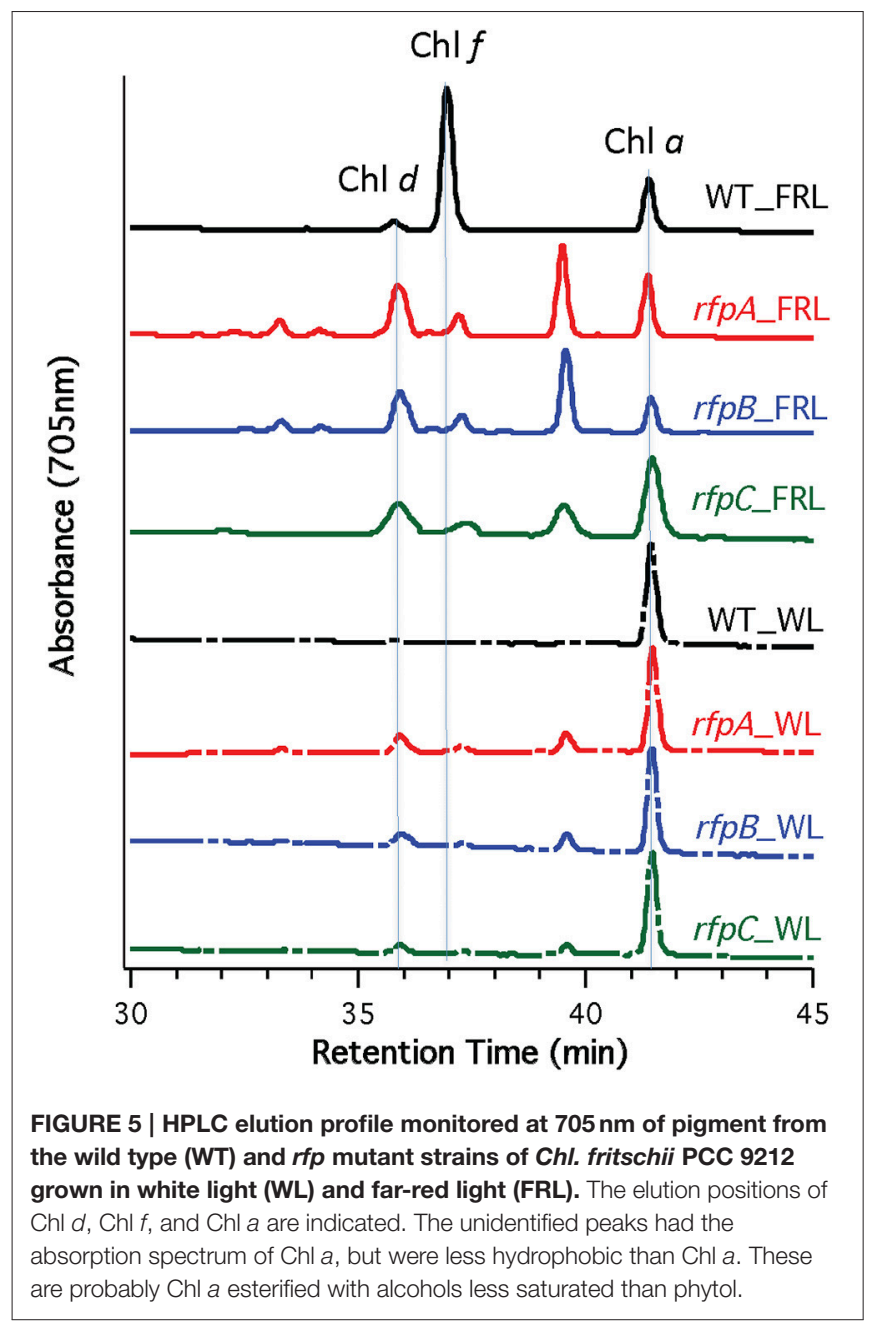

to extract expression levels for each gene as described previously (20). In the rRNA depleted WL sample $(T=0 \mathrm{~h}), 10,504,251$ reads were obtained, of which 7,221,701 reads (69\%) were uniquely mapped to mRNA. For the rRNA-depleted samples of cells grown in FRL 10,033,440, 9,619,193, and 13,070,108 total reads were obtained and 9,941,370 (99\%), 9,545,774 (99\%), and $13,034,557$ (99\%) reads were uniquely mapped to mRNA for $T=12 \mathrm{~h}, T=24 \mathrm{~h}, T=48 \mathrm{~h}$, respectively. For the sample from cells grown in FRL for 2 weeks (sample FR), 12,171,511 total reads were obtained and 12,096,759 (99\%) reads were uniquely mapped to mRNA. The RNA sequencing data were deposited in the NCBI Sequence Read Archive (SRA) under accession number SRP062739.

\section{Isolation of Total RNA and PCR Analysis}

For gene expression analysis, total RNA was isolated from cells of the wild type and mutant strains grown to midexponential growth phase using a High Pure RNA isolation kit (Roche Diagnostics, Indianapolis, IN). To eliminate trace amounts of contaminating chromosomal DNAs, RNA samples were incubated with RNase-free DNase I (Promega, Madison, WI) for $1 \mathrm{~h}$ at room temperature. DNase-treated RNA samples were further purified using RNA purification cartridges. The absence of DNA in RNA samples was verified by PCR assays in which reverse transcriptase was omitted. The concentration of RNA was determined by NanoDrop measurements (Thermo Scientific, Watham, MA).

RT-PCR analysis of total RNA isolated from wild-type and mutant strains was performed using a MyTaq One-Step RT-PCR kit (Bioline USA Inc., Taunton, MA). Primers were designed to amplify specifically selected genes encoding major subunits of PS I, PS II and phycobilisomes as well as the 16S RNA gene as control (see Table S1). The amplicons from RT-PCR analysis were analyzed by agarose gel electrophoresis.

\section{RESULTS}

In a previous study, we established that Chl. fritschii PCC 9212 can grow in FRL and can synthesize Chl $d$, Chl $f$, and FRL-absorbing phycobiliproteins (Gan et al., 2015). This cyanobacterium contains a complete FaRLiP gene cluster that includes the 17 common FaRLiP genes encoding core components of the photosynthetic apparatus (Figure 1A) as well as the $r f p B A C$ operon. To obtain a more comprehensive view of the FaRLiP response in Chl. fritschii PCC 9212, we performed a transcription profiling study of this strain. Table S2 presents the complete data for samples collected from cells grown in WL as well as from cells grown in FRL for 12, 24, 48, and $336 \mathrm{~h}$. Figure 2 shows that photosynthesis genes can be described as belonging to one of two families: the FaRLiP paralogs (upper left quadrant, darker colors) which are only expressed in FRL, and the "WL paralogs", which are transcribed in both WL and FRL but are responsible for the photosynthetic apparatus found in cells grown in WL (lighter colored symbols). Some "WL paralogs" are single-copy genes and thus must be transcribed under both conditions to produce active photosynthetic complexes. The true "WL paralogs" that have homologs in the FaRLiP cluster generally 
show reduced transcription in FRL, but their transcription still occurs (this will be important in interpreting RT-PCR data in Figure 6 below). The enormous difference in transcript levels of the FaRLiP paralogs relative to the "WL paralogs" accounts for the remodeling of the photosynthetic apparatus that occurs in cells grown in FRL.

Transcripts for the FaRLiP gene cluster are already elevated by $12 \mathrm{~h}$ and reached a maximum at about $48 \mathrm{~h}$. Figure 2 shows a scatter-plot comparison of the relative transcript abundances for Chl. fritschii PCC 9212 cells grown in FRL for $48 \mathrm{~h}$ compared to cells grown in WL. The transcript levels for many genes unrelated to photosynthesis increased by more than two-fold ( $~ 972$ total genes), and transcript abundances for many genes decreased by more than 50\% ( $\sim 2720$ total genes; see Table S2 for details). Thus, more than half $(\sim 55 \%)$ of genes in this organism change transcript level by at least a factor of two when cells are grown in FRL for $48 \mathrm{~h}$. Thus, the FaRLiP response represents a major restructuring of not only the photosynthetic apparatus but of cellular composition and metabolism in general, as reported for Leptolyngbya sp. JSC-1 (Gan et al., 2014).

The dark-colored pentagonal markers in Figure 2 indicate the photosynthesis genes encoded in the FaRLiP gene cluster, with blue pentagons representing core subunit genes of the phycobilisome, green pentagons representing core subunit genes of PS II, and red pentagons representing core subunit genes of PS I. The dark brown pentagons represent the rfp genes (note that this organism has genes encoding two CheY-like receptors in the gene cluster shown in Figure 1A: $r f p C$, and a second gene that shows $\sim 62 \%$ sequence similarity with $r f p C$, so four genes are represented on Figure 2. Among these genes, the two most highly transcribed genes, $p s a A 2$ and $p s a B 2$, show an increase of $>5200$-fold, and even the regulatory $r f p$ genes show increases of more than 50-fold (see Table S2). This latter observation strongly implies that the $r f p$ genes are auto-regulated and that cells produce more of these regulatory proteins when they are grown in FRL. The triangular symbols, using similar coloring for the photosynthetic complexes, represent the paralogous genes for subunits of complexes that are normally expressed in WL (or that are expressed in a light-independent manner; most of these genes are also expressed in FRL). The majority of the genes for PS I and PBP subunits have substantially lower relative transcript abundances in cells grown in FRL. For example, the $p s a A 1$ and psaB1 transcripts are about 37-fold and 19-fold less abundant (Table S2). On the other hand, transcript levels for many PS II genes are similar under WL and FRL. The three black circles represent the $a p c D 4-a p c B 3-i s i X$ genes of the LoLiP gene cluster (Olsen et al., 2015). Note that relative transcript levels for these three genes did not increase in cells grown in FRL.

\section{Construction and Validation of $r f p A, r f p B$, and $r f p C$ Mutants}

A major, unresolved issue from initial studies of FaRLiP was whether the products of the $r f p A-r f p B-r f p C$ genes are the master control elements for this acclimation response. To address this question, we used biparental conjugation with E. coli to introduce DNA into Chl. fritschii PCC 9212 and to delete the $r f p A, r f p B$, and $r f p C$ genes (see Figures 1B-D). An ermC gene cassette $\left(\mathrm{Em}^{\mathrm{R}}\right)$ was used to replace each gene individually. After

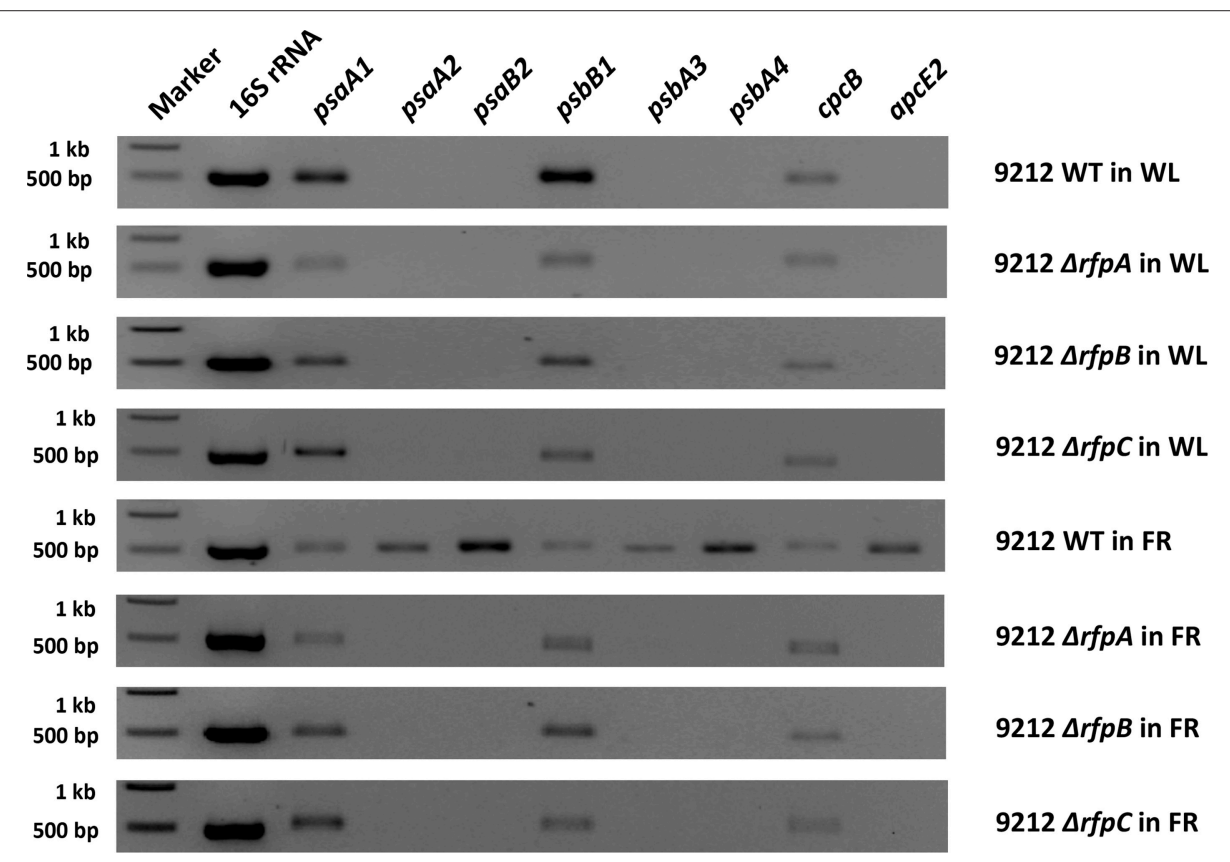

FIGURE 6 | Agarose gel electrophoresis of amplicons produced by RT-PCR using template RNAs from the indicated strains of Chl. fritschii PCC 9212 grown in white light (WL) or far-red light (FRL). Genes psaA2, psaB2, psbA4, psbA5, and apcE2 are found in the FaRLiP gene cluster (see Figure 1A) and are specifically expressed in FRL in the wild type but not in any of the mutant strains. Genes psaA1, $p s b B 1$, and $c p c B$ are expressed under all conditions in all strains because they are not part of the FaRLiP response. 
mating, selection, and repeated streaking, antibiotic-resistant transconjugants were obtained. Figure 1E shows the results of analytical agarose gel electrophoresis of PCR amplicons derived using forward and reverse primers for $r f p A$ (see Table S1) with WT and transconjugant DNAs as templates. The results show that complete gene replacement had occurred without sucrose counter-selection and that wild-type and mutant alleles had fully segregated. Thus, RfpA is not essential for cell viability when cells are grown in WL. Figures 1F,G show similar PCR results for the $r f p B$ and $r f p C$ genes, which likewise are not essential for cell viability when cells are maintained in WL.

\section{Physiological Characterization of Rfp Mutants}

To assess the effects of deleting the $r f p A, r f p B$, and $r f p C$ genes, wild type and mutant cells were grown in WL and then transferred to FRL. After 4 days of growth, whole-cell absorption and low-temperature fluorescence emission spectra were recorded. As shown in Figure 3, only the wild-type strain could alter its photosynthetic apparatus to increase absorption above $700 \mathrm{~nm}$ when cells were grown in FRL. The wild-type cells grown in FRL also showed a fluorescence emission band with a maximum at $739 \mathrm{~nm}$ (Figure 4A), which is indicative of the synthesis of Chl $f$ and the biogenesis of new photosystem complexes (Gan et al., 2015). In contrast, fluorescence emission spectra for the three mutant strains (Figures 4B-D) showed no evidence that $\mathrm{Chl} f$ was being synthesized when cells were incubated in FRL. Increasing the time of incubation in FRL did not lead to Chl $f$ synthesis or to changes in the photosynthetic apparatus for the mutant strains. In fact, the mutant cultures slowly became chlorotic over time because the cells were unable to grow in FRL.

Figure 5 shows HPLC elution profiles monitored at $705 \mathrm{~nm}$, which is the peak absorption value for Chl $f$ in the solvents used for the analysis. As expected, wild-type cells grown in WL only synthesized Chl $a$, but wild-type cells grown in FRL showed peaks characteristic of Chl $d$, Chl $f$, and Chl $a$ at 36, 37, and $42 \mathrm{~min}$, respectively. Analyses of Chls in cells of the $r f p A, r f p B$ and $r f p C$ mutant grown in WL surprisingly showed the presence of both Chl $d$ and Chl $a$, but importantly, no Chl $f$ was detected in cells grown in WL or FRL. However, when the mutants were grown in FRL, two new peaks were observed, eluting at 37.5 and $39 \mathrm{~min}$, both of which had absorption spectra identical to that of Chl $a$. From their elution behavior, these pigments are more hydrophilic than Chl $a$ and mostly likely represent Chl $a$ esterified with alcohols more unsaturated than phytol. These alternative
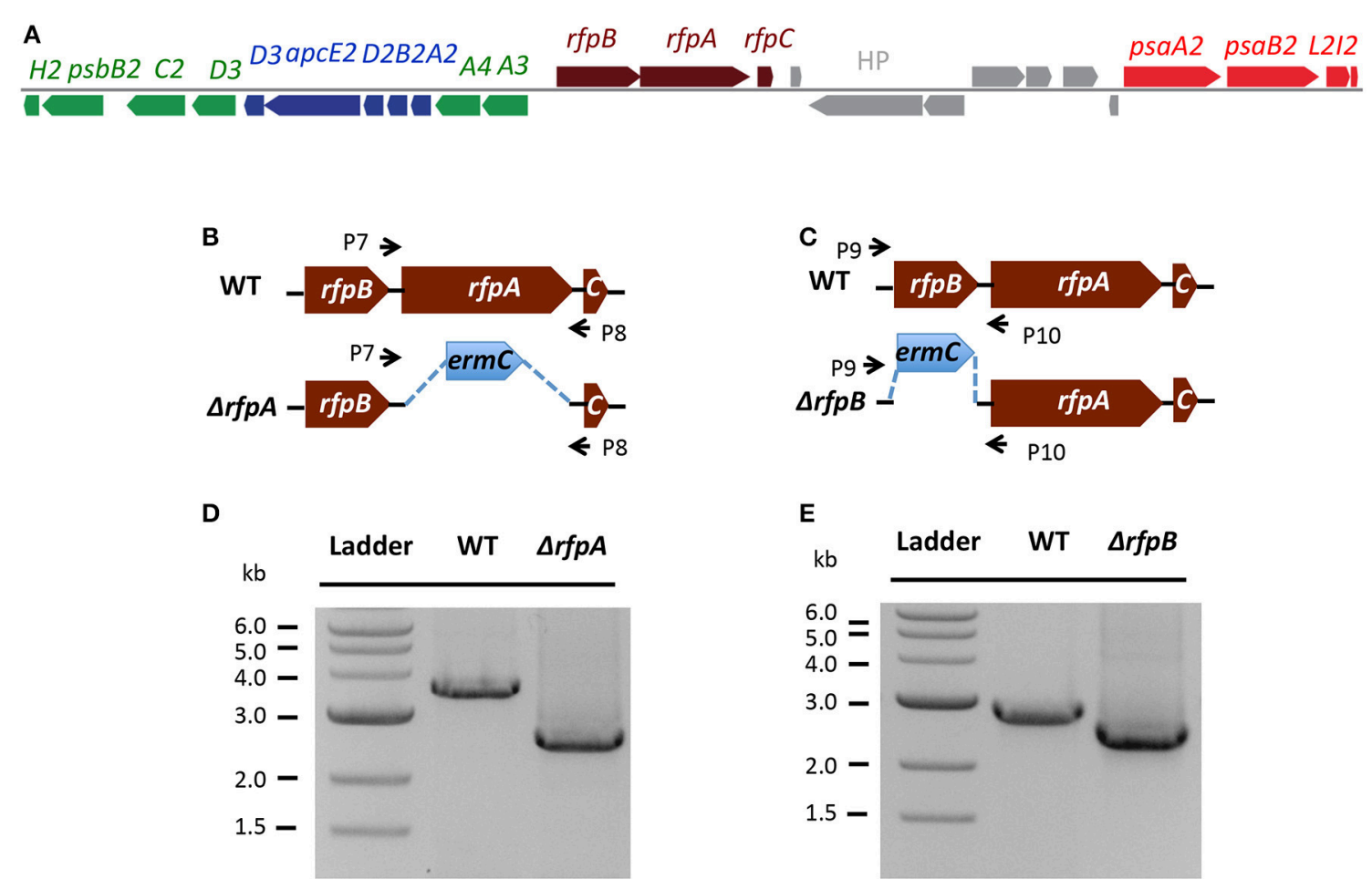

FIGURE 7 | The organization of the FaRLiP gene cluster in Chr. thermalis PCC 7203 and construction and validation of $r f p A$ and $r f p B$ deletion mutants. (A) Organization of the FaRLiP gene cluster. Red boxes represent genes encoding core subunits of PS I; green boxes represent genes encoding core subunits of PS II; blue boxes represent genes encoding core components of the phycobilisome; brown boxes represent regulatory rfp genes; and gray boxes represent hypothetical genes. (B) Schematic showing deletion of $r f p A$. The small arrows (P7 and P8) indicate the positions of the primers used for PCR verification of deletion. (C) Schematic showing deletion of $r f p B$. The small arrows (P9 and P10) indicate the positions of primers used for PCR verification of the deletion. (D) Agarose gel electrophoresis of amplicons showing complete segregation of wild-type and mutant rfpA alleles. (E) Agarose gel electrophoresis of amplicons showing complete segregation of wild-type and mutant $r f p B$ alleles. 
forms of Chl a were also observed when wild-type cells were grown photoheterotrophically, and they have also been observed in Synechococcus sp. PCC 7335 (data not shown). The significance of these forms of Chl $a$ is presently unknown.

\section{RT-PCR Analyses of FaRLiP Gene Expression}

To assess whether $\mathrm{RfpA}, \mathrm{RfpB}$, and $\mathrm{RfpC}$ are involved in controlling transcription of the FaRLiP gene cluster, we isolated RNA from wild-type and mutant cells grown in WL or FRL and performed reverse-transcriptase- (RT) PCR assays. Five genes from the FaRLiP gene cluster were selected for analysis: $p s a A 2$, $p s a B 2, p s b A 3, p s b A 4$, and apcE2. As controls, three paralogous genes normally expressed in WL were also analyzed: $p s a A 1$, $p s b B 1$, and $a p c E 1$. As expected, transcripts were not detected for genes from the FaRLiP cluster when wild-type cells were grown in WL, but transcripts for all five genes were highly abundant in RNA isolated from wild-type cells grown in FRL (Figure 6). By varying the number of cycles in the PCR reactions, we estimated that these transcripts were at least 1000 -fold more abundant under these conditions, which agrees well with the data in Figure 2. In contrast, no transcripts were detected in RNA isolated from the $r f p A, r f p B$, or $r f p C$ mutant strains when cells were grown in FRL or WL. Combining previous results on RfpA showing it is a red/far-red phytochrome (Gan et al., 2014), and domain analysis of $\operatorname{RfpB}$ (see Introduction), these results confirm that $\mathrm{RfpB}$ is a transcription activator for the genes of the FaRLiP gene cluster, and that RfpA is the light sensor for this acclimation process. In contrast, transcripts for the paralogous genes normally expressed in WL were detected in RNA samples for the wild type and the mutants regardless of the growth light conditions. These results are also consistent with the transcription profiling results shown in Figure 2, and they establish that the RNA samples were not degraded. Other control experiments omitting reverse transcriptase showed that the RNA templates were free from contaminating DNA (data not shown). Collectively, these results establish that $\mathrm{RfpA}, \mathrm{RfpB}$, and RfpC are the master control elements of the FaRLiP response.

Figure 7A shows the arrangement of genes in the FaRLiP cluster of Chr. thermalis PCC 7203. Overall, this cluster is very similar to that in Chl. fritschii PCC 9212, but two PS I genes, psaJ2 and $p s a F 2$, are missing from the cluster and are located elsewhere on the genome. Previous studies showed that conjugation from $E$. coli could be used to introduce DNA into some Chroococcidiopsis spp., although Chr. thermalis PCC 7203 was not specifically tested (Billi et al., 2001; Billi, 2010). Deletion of the $r f p A$ and $r f p B$ genes from Chr. thermalis PCC 7203 confirmed that RfpA and RfpB are the master control elements for FaRLiP in this organism as well. Briefly, fully segregated mutants were obtained for both genes (see Figures 7B-E). When these mutants were grown in FRL, cells were unable to increase their absorption above $700 \mathrm{~nm}$ (Figure 8), did not exhibit fluorescence emission characteristic of Chl $f$ (Figure 9), were unable to synthesize Chl $f$ (Figure 10) and as a result were unable to grow in FRL. However, as observed for Chl. fritschii PCC 9212, inactivation of the $r f p A$ and $r f p B$ genes in Chr. thermalis PCC 7203 led to derepression of Chl

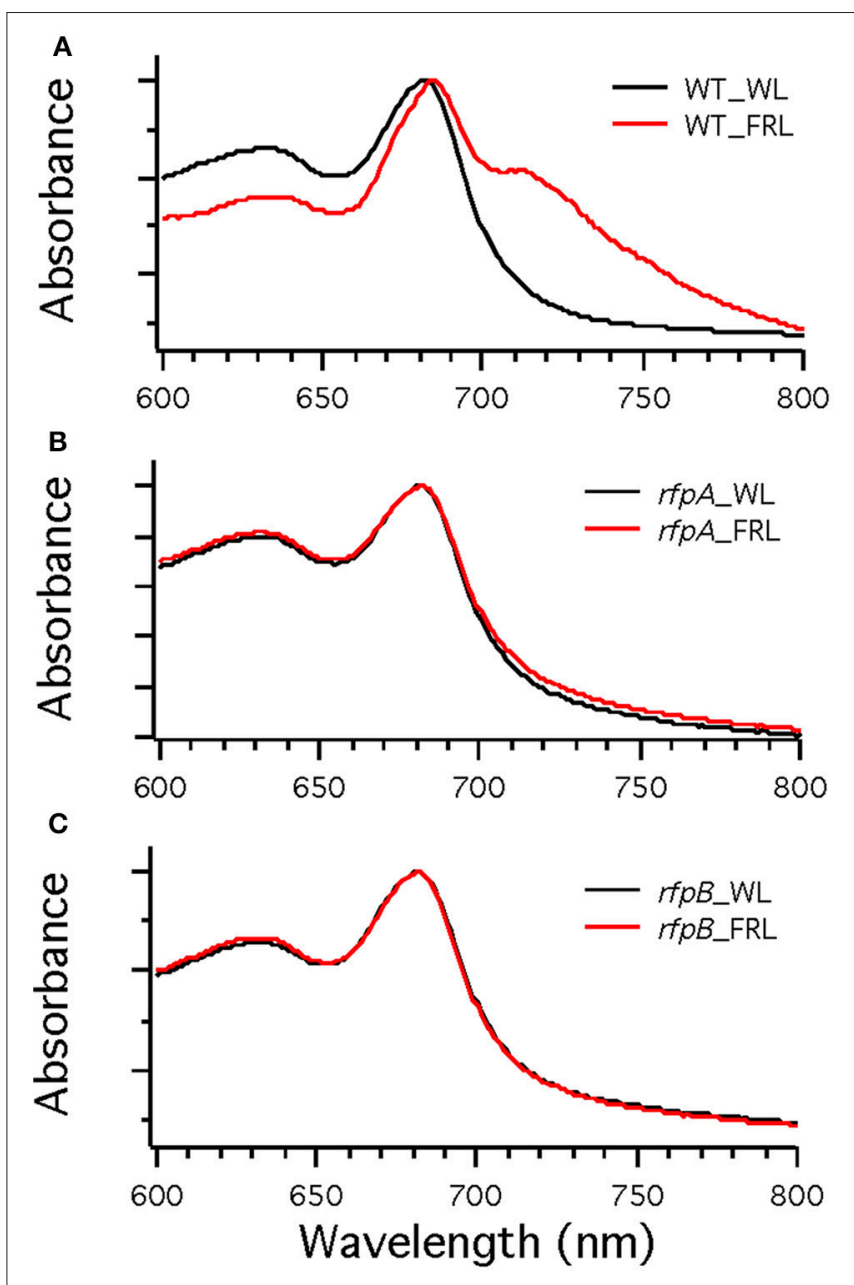

FIGURE 8 | Whole cell absorption spectra of wild-type (WT) (A) and the $r f p A(B)$ and $r f p B(C)$ mutant strains of Chr. thermalis PCC 7203. Cells were grown in white light (WL; black lines) or far-red light (FRL; red lines). Note that only the WT can modify its photosynthetic apparatus when grown in FRL.

$d$ synthesis in WL (Figure 10). These results are in complete agreement with those obtained for Chl. fritschii PCC 9212 and suggest that regulation of the FaRLiP response in other FaRLiP cyanobacteria will be similar to that described here.

\section{DISCUSSION}

The FaRLiP acclimation response is a transcription program triggered by FRL that leads to an extensive remodeling of the photosynthetic apparatus of cells that have the ability to synthesize Chl $f$ and Chl $d$ and that have the requisite gene cluster. The synthesis of paralogous forms of PS I, PS II, and phycobiliprotein core proteins, in addition to the synthesis of Chl $f$ and $\mathrm{Chl} d$, produces cells with enhanced absorption between 700 and $800 \mathrm{~nm}$, and these changes collectively enables cells to grow in FRL (Gan et al., 2014, 2015; Gan and Bryant, 2015). Based upon the results obtained in this study, RfpA, RfpB, and $\mathrm{RfpC}$ are critically important regulatory proteins in the FaRLiP response. 


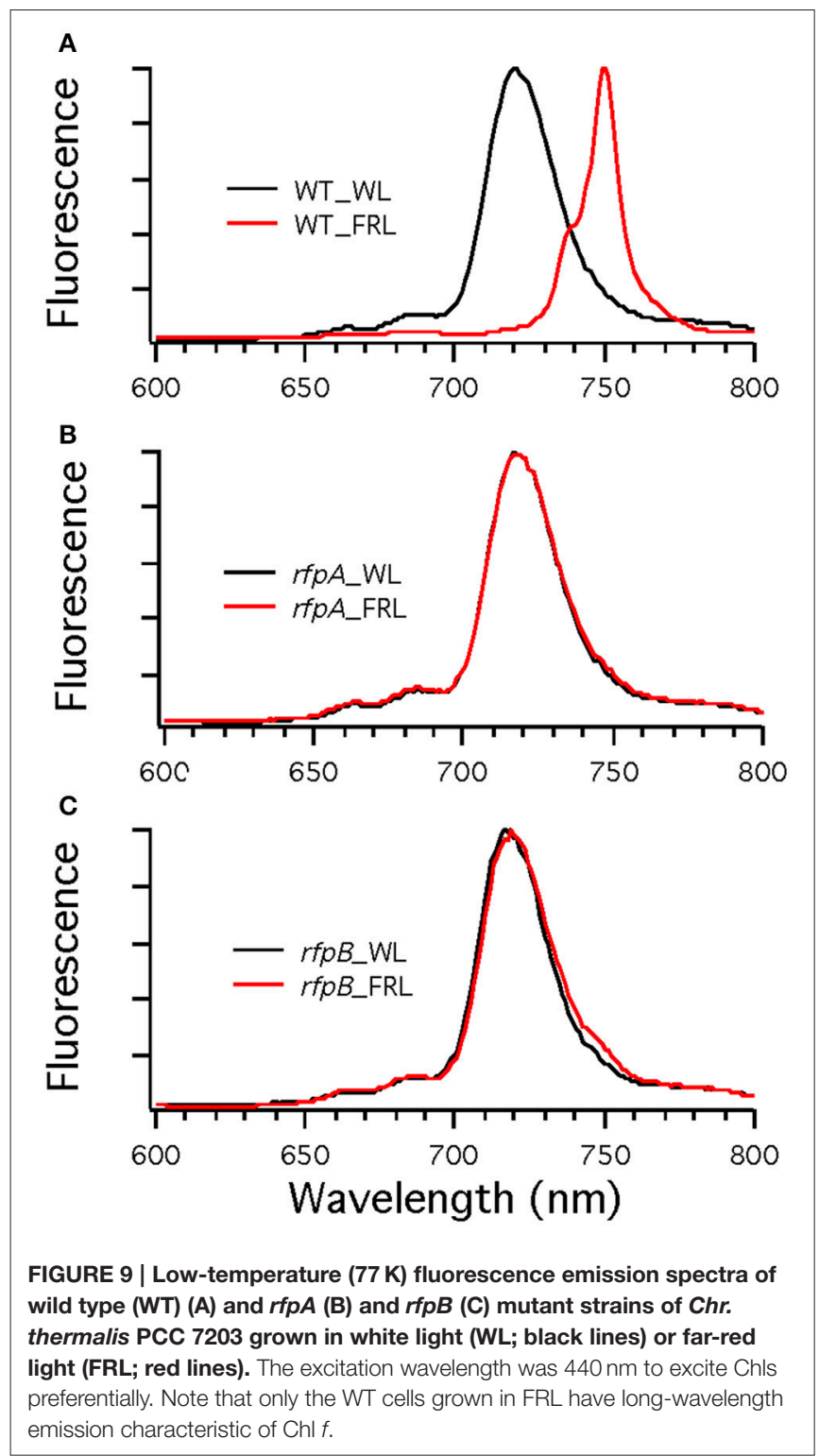

Figure 11 shows a model for regulation of FaRLiP response by $\mathrm{RfpA}, \mathrm{RfpB}$, and $\mathrm{RfpC}$. RfpA is a knotless phytochrome, which forms a unique structural class within the large family of cyanobacterial photoreceptors (Gan et al., 2014). RfpA has the domain structure GAF-PHY-PAS-Histidine-Kinase, which is distinct from that of the knotted phytochrome photoreceptor, RcaE, of complementary chromatic acclimation, which has the domain organization PAS-GAF-PAS-Histidine-Kinase (Gutu and Kehoe, 2012; Gan et al., 2014). Thus, these two photoreceptors that control photoacclimation responses in cyanobacteria are not closely related evolutionarily. It appears that these two acclimation responses arose independently, and there is no overlap in the genes controlled by the two photoreceptors. To date, orthologs of RfpA are only found in the genomes of the 13 cyanobacteria that possess FaRLiP gene clusters and RcaE has only been observed in some but not all cells

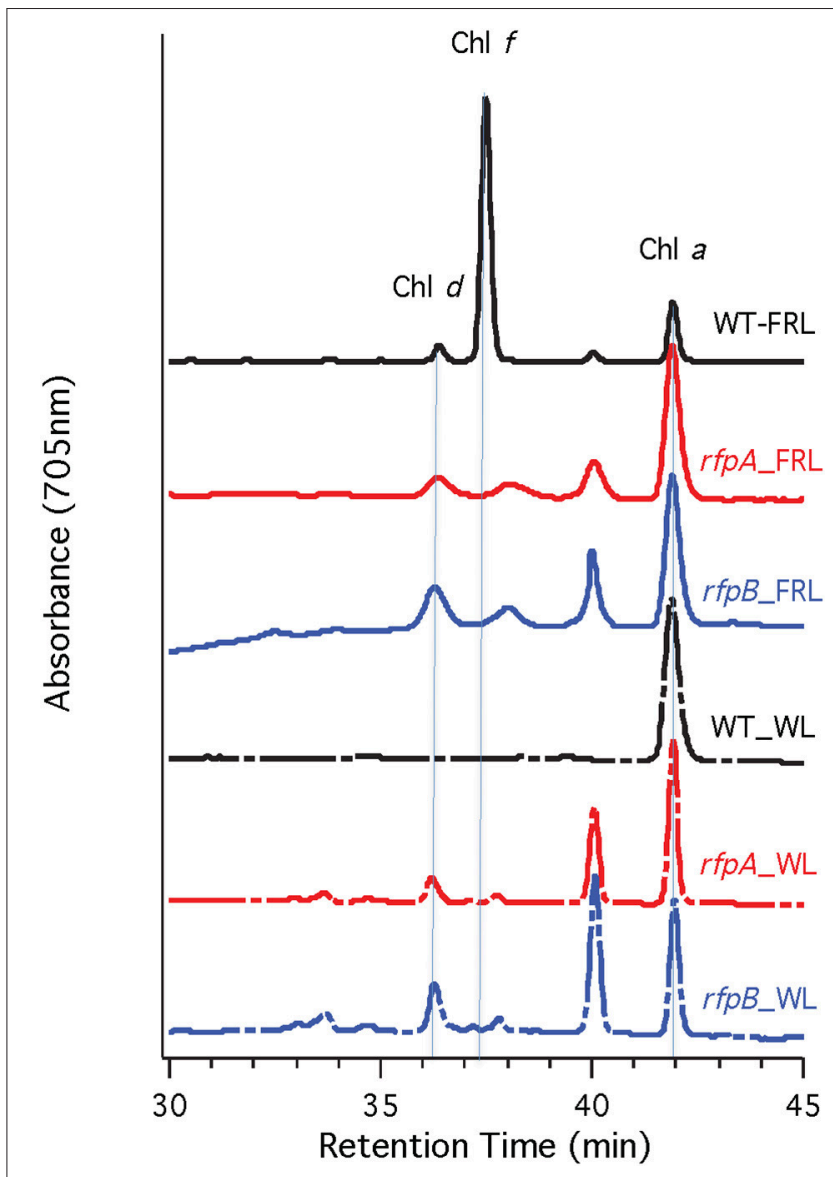

FIGURE 10 | HPLC elution profile monitored at $705 \mathrm{~nm}$ of pigments from the wild type (WT) and rfpA and rfpB mutant strains of Chr. thermalis PCC 7203 grown in white light (WL) and far-red light (FRL). The elution positions of $\mathrm{Chl} d, \mathrm{Chl} f$, and $\mathrm{Chl}$ a are indicated by the vertical dotted lines. The unlabeled peaks at 37.5 and 40 min had the absorption spectrum of $\mathrm{Chl}$ a and likely represent $\mathrm{Chl}$ a esterified with alcohols less saturated than phytol.

that synthesize phycoerythrin. We previously showed that the GAF domain of RfpA binds a phycocyanobilin chromophore to form a red/far-red responsive photoreceptor (Gan et al., 2014). A broad range of light wavelengths can produce the far-red-absorbing $\left(\mathrm{P}_{\mathrm{fr}}\right)$ form of $\mathrm{RfpA}$, but only FRL $(\lambda \geq$ $700 \mathrm{~nm}$ ) produces the red absorbing $\left(\mathrm{P}_{\mathrm{r}}\right)$ form (see Gan et al., 2014). Thus, in the model shown in Figure 11, absorption of FRL activates the histidine kinase to transfer a phosphate to $\mathrm{RfpC}$, which in turn transfers the phosphate to RfpB. RfpC is a member of the CheY family and is likely to undergo reversible phosphorylation. Note that FRL could also inactivate the histidine kinase, which would allow a phosphatase activity to remove the phosphate from $\mathrm{RfpB}$ and $\mathrm{RfpC}$. At present, we do not know which state, phosphorylated or unphosphorylated, of $\mathrm{RfpB}$ is the transcriptional activator, nor do we know the exact role of $\mathrm{RfpC}$, but these details can be ascertained from future studies.

$\mathrm{RfpB}$ is a DNA-binding response regulator, which contains two CheY receiver domains that flank a winged-helix, 


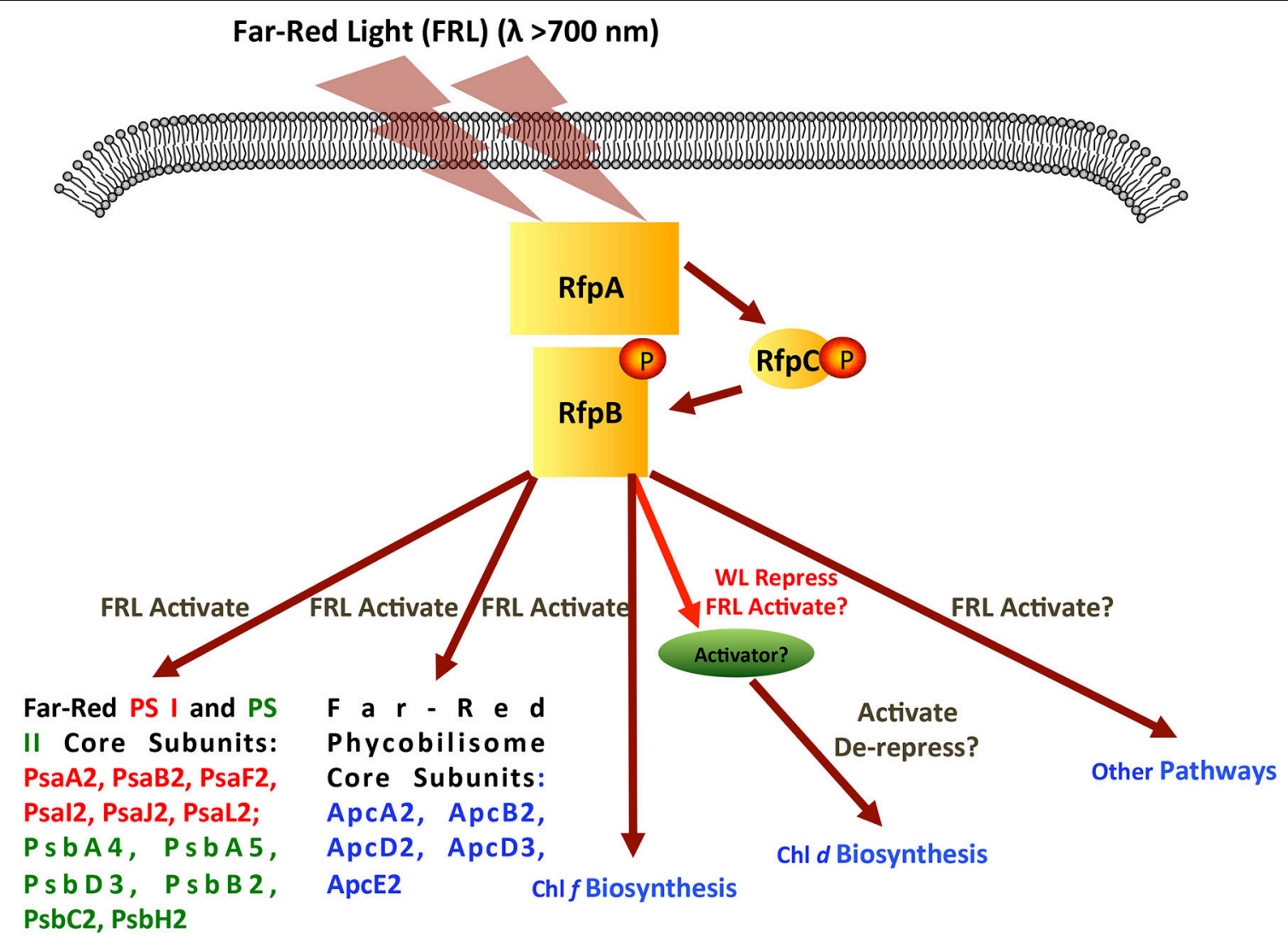

FIGURE 11 | Scheme showing the signal transduction cascade formed by RfpA, RfpB, and RfpC. Although the figure shows the RfpB being activated by phosphorylation, it is possible that the active form would be dephosphorylated. In this model, far-red light activates the histidine kinase of RfpA, which in turn phosphorylates RfpC, and finally phosphorylates the response regulator/transcription activator RfpB. Genes and process regulated by activated RfpB are indicated.

DNA-binding domain. RfpB apparently acts as a transcription activator of all of the genes of the FaRLiP cluster, because deletion of the $\operatorname{rfp} B$ gene did not lead to derepression of any of the genes of the FaRLiP gene cluster. RfpB either directly or indirectly must also regulate the genes for the synthesis of Chl $f$, which was not synthesized by the mutants in WL or FRL. Surprisingly, the synthesis of Chl $d$ was derepressed in all $r f p$ mutants in both cyanobacteria tested. This resulted in the inappropriate synthesis of $\mathrm{Chl} d$ in cells grown in WL.

The results presented here establish that conjugation can be used to delete genes in Chl. fritschii PCC 9212 and in Chr. thermalis PCC 7203. These studies confirm and significantly extend the results of Stucken et al. (2012) and Billi et al. (2001), who demonstrated conjugation-based transfer of DNA into Chl. fritschii PCC 6912 and Chroococcidiopsis spp., respectively. In other studies, we have found that conjugation also works well in Synechococcus sp. PCC 7335 (M.-Y. Ho, C. Zhao, and D. A. Bryant, unpublished results), and we have produced $r f p A, r f p B$, and $r f p C$ mutants in this strain as well. We are currently testing whether conjugation can be used to produce mutants in Fischerella thermalis
PCC 7521, a thermophilic FaRLiP strain that could be used to produce protein complexes for crystallization. Fischerella (Mastigocladus) spp. have previously been used successfully for this purpose (Almog et al., 1991; Kurisu et al., 2003; Kim et al., 2013). Thus, it should be possible to use mutational and biochemical analyses to characterize the modified photosynthetic complexes produced in diverse FaRLiP strains grown in FRL.

Although several options are now available for strains that could serve as model organisms for the FaRLiP response, Chl. fritschii PCC 9212 appears to be the optimal choice. Chlorogloeopsis spp. are filamentous but this aspect is often only apparent in hormogonia, which form short chains of barrel-shaped cells (Evans et al., 1976). After losing motility, these cells enlarge to become spherical vegetative cells within an extracellular sheath. Heterocysts develop both in terminal and intercalary positions. As growth continues, cell division in more than one plane occurs, and multiseriate trichomes form, which causes loss of the filamentous nature as the trichomes fragment into amorphous aggregates. Chlorogloeopsis spp. are very good chemoheterotrophs, growing well on sucrose as well as acetate and other sugars, including glucose, fructose, and 
ribose (Hoffman and Castenholz, 2001; Zhang and Bryant, 2015). Interestingly, growth on sucrose suppresses the formation of trichomes (Evans et al., 1976), a trait that could improve the efficiency of conjugation. Chl. fritschii PCC 9212 has gene clusters for both the FaRLiP and LoLiP responses, and it grows well on plates and in liquid media. These properties make it an excellent choice as a model organism for studies of FaRLiP and LoLiP.

\section{AUTHOR CONTRIBUTIONS}

CZ, FG, and GS performed the research. DB directed the research and wrote the initial draft of the manuscript. All authors participated in editing and correcting the draft.

\section{REFERENCES}

Almog, O., Shoham, G., Michaeli, D., and Nechushtai, R. (1991). Monomeric and trimeric forms of photosystem I reaction center of Mastigocladus laminosus: crystallization and preliminary characterization. Proc. Natl. Acad. Sci. U.S.A. 88, 5312-5316. doi: 10.1073/pnas.88.12.5312

Billi, D. (2010). "Genetic tools for desiccation- and radiation-tolerant cyanobacteria of the genus Chroococcidiopsis," in Current Research, Technology and Education Topics in Applied Microbiology and Microbial Biotechnology, 2010 Edition, ed A. Méndez-Vilas (Badajoz: Formatex Research Center), 1517-1521.

Billi, D., Friedmann, E. I., Helm, R. F., and Potts, M. (2001). Gene transfer to the desiccation-tolerant cyanobacterium Chroococcidiopsis. J. Bacteriol. 183, 2298-2305. doi: 10.1128/JB.183.7.2298-2305.2001

Dubbs, J. M., and Bryant, D. A. (1991). Molecular cloning and transcriptional analysis of the cpeBA operon of the cyanobacterium Pseudanabaena species PCC 7409. Mol. Microbiol. 5, 3073-3085. doi: 10.1111/j.1365-2958.1991. tb01867.x

Elhai, J., Vepritskiy, A., Muro-Pastor, A. M., Flores, E., and Wolk, C. P. (1997). Reduction of conjugal transfer efficiency by three restriction activities of Anabaena sp. strain PCC 7120. J. Bacteriol. 179, 1998-2005.

Elhai, J., and Wolk, C. P. (1988). Conjugal transfer of DNA to cyanobacteria. Meth. Enzymol. 167, 747-754. doi: 10.1111/1462-2920.12600

Evans, E. H., Foulds, I., and Carr, N. G. (1976). Environmental conditions and morphological variation in the blue-green alga Chlorogloea fritschii. J. Gen. Microbiol. 92, 147-155. doi: 10.1099/00221287-92-1-147

Fewer, D., Friedl, T., and Büdel, B. (2002). Chroococcidiopsis and heterocystdifferentiating cyanobacteria are each other's closest living relatives. Mol. Phylogenet. Evol. 23, 82-90. doi: 10.1006/mpev.2001.1075

Friedmann, E. I., and Ocampo-Friedmann, R. (1995). A primitive cyanobacterium as pioneer microorganism for terraforming Mars. Adv. Space Res. 15, 243-246. doi: 10.1016/S0273-1177(99)80091-X

Friedmann, E. I., Ocampo-Friedmann, R., and Hua, M. (1994). Chroococcidiopsis, the most primitive living cyanobacterium? Orig. Life Evol. Biosph. 24, 269-270.

Gan, F., and Bryant, D. A. (2015). Adaptive and acclimative responses of the photosynthetic apparatus in cyanobacteria to far-red light. Environ. Microbiol. 17, 3450-3465. doi: 10.1111/1462-2920.12992

Gan, F., Shen, G., and Bryant, D. A. (2015). Occurrence of far-red light photoacclimation (FaRLiP) in diverse cyanobacteria. Life 5, 4-24. doi: 10.3390/ life 5010004

Gan, F., Zhang, S., Rockwell, N. C., Martin, S. S., Lagarias, J. C., and Bryant, D. A. (2014). Extensive remodeling of a cyanobacterial photosynthetic apparatus in far-red light. Science 345, 1312-1317. doi: 10.1126/science.1256963

Graham, J. E., and Bryant, D. A. (2008). The biosynthetic pathway for synechoxanthin, an aromatic carotenoid synthesized by the euryhaline, unicellular cyanobacterium Synechococcus sp. PCC 7002. J. Bacteriol. 190, 7966-7974. doi: 10.1128/JB.00985-08

\section{ACKNOWLEDGMENTS}

This research was supported by grant MCB-1021725 from the National Science Foundation to DB. This research was also conducted under the auspices of the Photosynthetic Antenna Research Center (PARC), an Energy Frontier Research Center funded by the DOE, Office of Science, and Office of Basic Energy Sciences under Award Number DE-SC 0001035.

\section{SUPPLEMENTARY MATERIAL}

The Supplementary Material for this article can be found online at: http://journal.frontiersin.org/article/10.3389/fmicb. 2015.01303

Gutu, A., and Kehoe, D. M. (2012). Emerging perspectives on the mechanisms, regulation, and distribution of light color acclimation in cyanobacteria. Mol. Plant 5, 1-13. doi: $10.1093 / \mathrm{mp} / \mathrm{ssr} 054$

Hoffman, L., and Castenholz, R. W. (2001). "Chlorogloeopsis Mitra and Pandey 1966," in Bergey's Manual of Systematic Bacteriology, 2nd Edn., Vol. 1, eds D. R. Boone and R. W. Castenholz (Berlin: Springer), 591-592.

Kim, Y., Ye, Z., Joachimiak, G., Videau, P., Young, J., Hurd, K., et al. (2013). Structures of complexes comprised of Fischerella transcription factor HetR with Anabaena DNA targets. Proc. Natl. Acad. Sci. U.S.A. 110, 1716-1723. doi: $10.1073 /$ pnas. 1305971110

Kühl, M., and Jørgensen, B. B. (1994). The light field of microbenthic communities: radiance distribution and microscale optics of sandy coastal sediments. Limnol. Oceanogr. 39, 1368-1398. doi: 10.4319/lo.1994.39.6.1368

Kurisu, G., Zhang, H., Smith, J. L., and Cramer, W. A. (2003). Structure of the cytochrome $b_{6} f$ complex of oxygenic photosynthesis: tuning the cavity. Science 302, 1009-1014. doi: 10.1126/science.1090165

Li, H., and Durbin, R. (2009). Fast and accurate short read alignment with Burrows-Wheeler transform. Bioinformatics 25, 1754-1760. doi: 10.1093/bioinformatics/btp324

Ludwig, M., and Bryant, D. A. (2011). Transcription profiling of the cyanobacterium Synechococcus sp. PCC 7002 using high-throughput cDNA sequencing. Front. Microbiol. 2:41. doi: 10.3389/fmicb.2011.00041

Mitra, A. K., and Pandey, D. C. (1967). On a new genus of the blue-green alga Chlorogloeopsis with remarks on the production of heterocysts in the alga. Phykos 5, 106-114.

Nowack, S., Olsen, M. T., Schaible, G., Becraft, E. D., Shen, G., Bryant, D. A., et al. (2015). Light adaptations of Synechococcus strains representative of ecological species inhabiting different depths in the Mushroom Spring microbial mat, Yellowstone National Park. Front. Microbiol. 6:626. doi: 10.3389/fmicb.2015. 00626

Olsen, M. T., Nowack, S., Wood, J. M., Becraft, E. D., LaButti, K., Lipzen, A., et al. (2015). Comparative genomics and in situ transcriptional analyses of Synechococcus isolates representative of different ecological species in the Mushroom Spring microbial mat. Front. Microbiol. 6:604. doi: 10.3389/fmicb. 2015.00604

Rippka, R. (1988). Isolation and purification of cyanobacteria. Meth. Enzymol. 167, 3-27. doi: 10.1016/j.biortech.2014.05.055

Rippka, R., Deruelles, J., Waterbury, J. B., Herdman, M., and Stanier, R. Y. (1979). Genetic assignments, strain histories and properties of pure cultures of cyanobacteria. J. Gen. Microbiol. 111, 1-61. doi: 10.1099/00221287111-1-1

Shen, G., Schluchter, W. M., and Bryant, D. A. (2008). Biogenesis of phycobiliproteins I. $c p c S$ and $c p c U$ mutants of cyanobacterium Synechococcus sp. PCC 7002 define a heterodimeric phycocyanobilin lyase specific for $\beta$-phycocyanin and allophycocyanin subunits. J. Biol. Chem. 283, 7503-7512. doi: 10.1074/jbc.M708164200

Stucken, K., Ilhan, J., Roettger, M., Dagan, T., and Martin, W. F. (2012). Transformation and conjugal transfer of foreign genes into the filamentous 
multicellular cyanobacteria (subsection V) Fischerella and Chlorogloeopsis. Curr. Microbiol. 65, 552-560. doi: 10.1007/s00284-012-0193-5

Zhang, S., and Bryant, D. A. (2015). Biochemical validation of the glyoxylate cycle in the cyanobacterium Chlorogloeopsis fritschii strain PCC 9212. J. Biol. Chem. 290, 14019-14030. doi: 10.1074/jbc.M115.648170

Zhao, Y., Shi, Y., Zhao, W., Huang, X., Wang, D., Brown, N., et al. (2005). CcbP, a calcium-binding protein from Anabaena sp. PCC 7120, provides evidence that calcium ions regulate heterocyst differentiation. Proc. Natl. Acad. Sci. U.S.A. 102, 5744-5748. doi: 10.1073/pnas.0501 782102
Conflict of Interest Statement: The authors declare that the research was conducted in the absence of any commercial or financial relationships that could be construed as a potential conflict of interest.

Copyright (๑) 2015 Zhao, Gan, Shen and Bryant. This is an open-access article distributed under the terms of the Creative Commons Attribution License (CC BY). The use, distribution or reproduction in other forums is permitted, provided the original author(s) or licensor are credited and that the original publication in this journal is cited, in accordance with accepted academic practice. No use, distribution or reproduction is permitted which does not comply with these terms. 